\title{
Parameters of Communication Behavior and National Language
}

\author{
Arkadiy Petrovich Sedykh, Zhao Yonghua, Daria Alekseevna Shchukina, Olga Ivanovna \\ Vorobeva, Sergey Borisovich Nikonov
}

\begin{abstract}
The article aims to analyze the category of "language behavior" in modern linguistic research. It states provisions of the communicative interpretation of the logical-semantic structure of utterances to determine their ethnocultural features. The author of the article suggests considering proposition, modus and dictum within the implementation of national communication behavior. It is shown that the propositive structure, modality and nomination methods selected for communication have certain ethnocultural features since different languages reflect their own immanent preferences in terms of logic, semantics and strategies for achieving communication goals. The author also outlines prospects for the application of this methodology in line with the identification of the dominant features of national linguistic identity.
\end{abstract}

Keywords: proposition, modus, dictum, ethnoculture, semantic structure of utterances, communication, linguistic identity.

\section{INTRODUCTION}

From the viewpoint of functioning in a speech act, a "speaking person" is a dynamic projection of the structure of a linguistic sign. We consider culture as an ethnic substrate in the semantics of a linguistic sign, which is realized as behavioral patterns (behavioral attitudes and guidelines). It is mainly language behavior that is the linguistic embodiment of the national character, psychology and mindset. In this case, the basic element for transmitting and identifying cultural information is national language $[1,2]$.

Language and culture are semiotic systems where symbolic relationships have a priority. The content plane of a linguistic sign reveals nationally specific features of a linguistic worldview in speech. Statements are full-fledged semiotic signs and have ethnocultural characteristics in their structure [3, 4].

This article discusses the logical-semantic and logical-communicative aspects of constructing utterances,

Manuscript published on November 30, 2019

* Correspondence Author

Arkadiy Petrovich Sedykh*, Belgorod National Research University, Belgorod, Russia.

Zhao Yonghua, Renmin University of China, Beijing, China.

Daria Alekseevna Shchukina, St. Petersburg Mining University, St Petersburg, Russia.

Olga Ivanovna Vorobeva, Federal State Budget Educational Institution of Higher Education "Northern State Medical University", Arkhangelsk, Russia.

Sergey Borisovich Nikonov, Saint-Petersburg State University, Saint-Petersburg, Russia.

(C) The Authors. Published by Blue Eyes Intelligence Engineering and Sciences Publication (BEIESP). This is an open access article under the CC-BY-NC-ND license http://creativecommons.org/licenses/by-nc-nd/4.0/ which are important structural elements of the analysis of a linguistic sign in the dynamics of its implementation and reflection of ethnocultural features of the speech behavior of national linguistic identity. In other words, we propose to interpret modus, dictum and proposition with due regard to their ethnocultural strata.

\section{PROPOSED MRTHODOLOGY}

Modus that conveys the speaker's attitude to the content of any given utterance (communicative function, conditions and goals of communication) and dictum denoting the event-related frame of utterances (nominative function, substantive relations between objects) are ethnocentric. However, proposition, as the universal logical structure of any given utterance, cannot convey a nationally specific worldview. In this regard, we consider each concept both separately and in their interrelation.

For a start, we should consider the concept of "proposition", its status in interpreting statement parts and the possibility of identifying elements of an ethnic stratum in propositive structures.

We should mention that some scholars identify dictum and proposition [5-7]. In this article, these concepts are distinguished, which is explained by the tasks and methodology of this research: dictum is considered as one of the nomination methods, while proposition, as the semantic format of utterances, is associated with the figurative element of the latter.

According to this logic, modern linguistics often utilizes the notion of proposition. W. Quine wrote, "The need for proposition was so acute because it was about the key category, in relation to which other logical concepts were comprehended. For example, the synonymy of sentences is usually defined by the identity of proposition" [8].

There are different interpretations and definitions of this concept related to the meaning of a sentence. Earlier linguists and logicians regarded the meaning of a sentence as aggregate meanings of its constituent words. Nowadays, the meaning of any given word is considered not as a semantically autonomous category but rather as a function of a semantically meaningful sentence. According to $\mathrm{L}$. Wittgenstein, "only a sentence can have a semantic meaning, words are meaningful only in the context of this sentence" [9]. Gradually, the attention of linguists shifted from the communicative structure of sentences to their semantic structure. Linguistic articles are mostly concerned with the study of sentences with relative (multivalent) predicates. S.D.

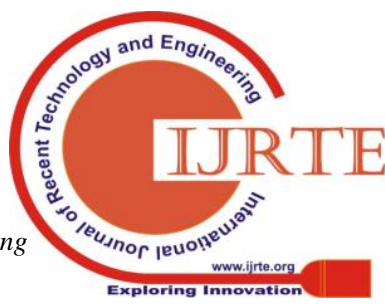




\section{Parameters of Communication Behavior and National Language}

Katsnelson stated that absolute predicates are not of great interest for semantic-syntactic research since they are single-place [10].

L. Wittgenstein formulated a fundamental difference between the simple function of a name and propositive sign: "The state of things can only be described, but not named (...) I name only objects, while signs replace them (...) A sentence can describe the existence of any given object rather than its essence" [9].

The notion of proposition is the basis of propositive semantics. Within the framework of this article, we highlight the semantic function of proposition and understand it as a generator of ethnocultural meanings. In conformity with the study objective, proposition is defined as the semantic structure of a speech sign combining denotative and significative meanings (the latter plays the key role).

Defining the term "proposition", we proceed from the C.D. Katznelson's concept: "...Proposition expresses a certain event or state as a relation between logically equal objects, (...) contains figurativeness and reflects reality more fully than a sentence. Like a picture, it depicts a whole episode without prescribing the direction and order of considering certain details" [11].

Thus, the propositive structure is a picture of juxtaposed "objects of thought" and "objective situations" reflecting a fragment of a real or psychological worldview as a configuration of semantic components.

Speaking about the need to link the specifics of nomination methods with the communication purpose of verbal signs, many scholars emphasize the inevitable task of researching nomination mechanisms based on the logical-syntactic organization of a sentence and forming its meaning from the actualized conceptual and linguistic content of verbal meanings connected through the chosen structure of proposition [12].

The initial concept for defining proposition is a speech act; therefore, this concept can be used to interpret the so-called "language games" [13]. Due to the specific approach to forming propositive schemes, each nation uses different language means in the process of serving communication (game) situations [14].

We believe that the chosen propositive structure has certain ethnocultural characteristics since different languages reflect their "individual" preferences in terms of logic, semantics and strategies for achieving communication goals. It is expressed by the specific configuration of semantic components of utterances in national languages, in particular, Russian and French. Proposition serves as a structural basis for implementing modal relations in speech behavior.

Being a part of a statement that performs the basic communicative function, modus is associated with modal values of statement components. First of all, it embraces modal words: perhaps, probably - il est possible, peut-être (assumption modus); doubtfully, likely - il est douteux, il est probable (presumption modus); one can see, one can hear on voit, on entend (perception modus), etc. However, the modal frame of statements is not limited to the direct functioning of descriptive semantics concerned with mental predicates and predicates of sensory perception. For instance, verbs of perception can develop epistemic meanings and introduce proposition.
According to N.D. Arutyunova, "the ability to acquire cognitive meanings is different for various verbs of perception. It depends on the primary meaning of each verb, in particular its semantic type, as well as the specifics of certain languages" [15]. It is realized in different ways and to varying degrees in national languages. Thus, the most epistemic Russian verbs are to smell and feel (see how it smells; feel how it sounds). The French verbs of visual perception are the most active from the epistemic perspective (regarde que c'est bon; tu vois je n'ai pas oublié).

We should note that modality in the Russian language is often associated with the verbal mood and, as a rule, introduces the reality/irreality opposition. In French, modality rather reflects the speaker's subjective attitude to some event (action). It can be indicated by the lack of a special subjective mood (Subjonctif) in the Russian language; therefore, the attitude of communicants to the subject of speech is mostly transmitted by lexical means.

Modality regulates the generation of speech acts by representatives of each national-cultural community, i.e. it has the ontological status of choosing a model of language behavior. The choice of modality is connected with the emotive aspect of communication: "Emotions have a cognitive basis: they are based on knowledge and assumption. Their cognitive component is primary in comparison to the emotive one" [15].

There are six types of modality:

1. Alethic modality (objectively: necessary, possible, impossible).

2. Deontic modality (subjectively: needed, allowed, prohibited).

3. Epistemic modality (subjectively: reliably, probably, exceptionally).

4. Axiological modality (subjectively: good, neutral, bad).

5. Time modality (objectively: the past, present, future).

6. Space modality (objectively: here, there, nowhere).

All types of modality are connected with the communication orientation of utterances and transmitted by various language units in different languages. In this case, we deal with multi-structured language systems: analytical French and synthetic Russian, where the national dictate performing the nominative function reflects specific methods of nomination with ethnocultural characteristics. The above-mentioned information is concerned with the discrepant technique of secondary nomination.

Secondary nomination can hardly be modeled and recorded in a dictionary as it is closely related to context, where the primary role is played by communicators (the author of some message) rather than general usage.

We also consider the semantic system developed by S.D. Katsnelson and directly related to the functioning of secondary nomination in speech since all types of secondary nomination are based on the associative nature of human thinking. As a result, meanings of linguistic units are represented as a flexible and probabilistic formation in the person's consciousness. In summary, this system can be demonstrated as follows: 
a) The main units of the semantic system of any language are lexical meanings (sememes), whose objective content coincide with formal notions;

b) There is no direct correlation between lexical and semantic units;

c) Lexical meanings reflect surrounding objects and relations that are comprehended in the process of perceiving objective reality in a peculiar, contradictory and incomplete form. Within certain limits, the content of words can be modified under the influence of formal factors and the reverse effect of language forms on their content;

d) The direct manifestation of thoughts is not a language system but a specific speech act and its product - a certain segment of speech (text); e) The inventory of semantic units is not arbitrary and is basically determined by the knowledge of the objective world and the development of thinking. The semantic system of any language is characterized by probabilistic determinism, which allows several implementations of the basic developmental pattern [10]. At the same time, the essential characteristics of dictum are determined by the national way of perceiving the world and peculiar mental operations of ethnocultural communities [16]. N.D. Arutyunova wrote that thoughts move from a communication plan to the nomination of some event to form the meaning of utterances and display it in a specific aspect based on the selected structure of proposition and the communicative perspective of utterances. The meaning of any given sentence is formed in the process of selecting and combining suitable nominative means that contribute to the nomination of the above-mentioned event and correct their meaning represented as a function of the meaning of sentences [12]. Thus, any language fixes possible deviations from the regular rules of integration, which have specific ethnic and cultural configurations. The desire to connect lexical meanings with communicative roles of verbal signs puts forward the task of studying the functioning of lexical units based on the logical and syntactic organization of sentences and meaning formation. These problems concern the interaction of nomination mechanisms and their logical-syntactic foundation, i.e. proposition that forms different types of indirect nominations. In this regard, the study of lexical metaphorical nominations becomes more relevant since they are closely connected with the reference of names and sentences. It is known that metaphorical nominations have national specifics. The nominative aspect of word meanings is their dynamic unfolding in the form of naming relationships, while the structure of naming relationships is a method of relating some name to its meaning and the meaning to reality expressed with that name. Direct nomination forms meanings directed towards the world in the same way as basic word meanings focus on the world (according to V.V. Vinogradov's terminology). However, word meanings are a means of storing non-linguistic information, i.e. knowledge, records and data about the world, and serve as a method of linguistic thinking [17]. Naming relationships enable one to rethink and form secondary sign functions of words. All secondary nominations are based on the meaning of the word whose name is used in a new naming function and is expressed in the dependent nominative function of such indirectly derived word meanings and the syntagmatic conditionality of their choice and combination during the construction of sentences [13]. The indirect reflection of reality is refracted under the influence of the content of the reference name. In this sense, the indirect (tropic) nomination can be considered as a special type of naming [18]. Spontaneous processes of secondary nomination are typical of any language but they are not random in selecting motivating characteristics and results. This motivation is manifested in the inner form of secondary nominations acting as an intermediary between a new meaning and its relation to reality. The reconsidered meaning of verbal signs not only adapts to the expression of new language content but also mediates it in the process of reflection. It should be noted that the motive of choosing a linguistic form can differ from the nucleus of the intermediate meaning, which is typical of the untyped sphere of nomination. A certain amount of significative content of the re-interpreted linguistic form acts as the inner form of a new meaning. The inner form of language units is the carrier of asymmetrical signs laying the basis of national ways of actualizing proposition and modus in dictum.

\section{RESULTS ANALYSIS}

At the highest level (speech-meaning), the semantics of language units is defined with due regard to contextual situations. The transition from the denotative level to the level of meaning is characterized by a qualitative semantic leap since this transition is made from the field of discrete and intermittent (typical of all language systems) to the area of a non-discrete, continuous meaning and referential universe.

Secondary nomination is a special attribute of word making but retains the utility function in relation to the entire system of language. The in-depth study of secondary nomination as a product of symbolic word-formation improves the interpretation and understanding of the meaning of utterances. The logical-syntactic basis of secondary nomination is the secondary proposition of utterances formed in the framework of implicit meanings of any given text. The structure of secondary proposition functions separately from the basic proposition of verbal messages and is related to the degree of propositivity of compositional speech structures. At the semantic level, the following opposition stands out within the framework of super-phrasal functioning mechanisms: zero (weakened) propositivity/strong propositivity. Based on this opposition, an individual narrative structure is formed. Sentences with a zero (weakened) degree of propositivity generate meanings at the denotative level: a pure logical operation based on simple combinations. Sentences with a strong degree of propositivity construct meanings based on intra- and extra-linguistic factors. The semantic fullness of such statements can be defined only in terms of individual-sensual sources. Semantically redundant utterances create the space of certain interpretation freedom and significantly influence the mechanism for creating the secondary nomination of language units. 


\section{Parameters of Communication Behavior and National Language}

\section{DISCUSSION}

The methodological perspective we have developed proceeds from the philosophical interpretation of cognition as a result of empirical and language experience and system-activity understanding of concept-sphere, language consciousness, speech and communication.

We focus on the integrative study of mental and speech-communicative mechanisms for generating utterances with the help of data from related disciplines. The key procedural element of this cognitive-communicative paradigm is the linguistic analysis of factual material accompanied by the synthesis of cognitive and functional research methods: lexicographic and contrastive description, the research of speech acts, the analysis of ordinary/artistic discourse. The integral idea of cognition, language, speech activity and communication aims to create a complex model of a linguistic identity, which is mediated through the above-mentioned phenomena in the ethnocultural field of their functioning.

The analysis of a linguistic identity implies the unification of methods borrowed from several sciences, with linguistics and communication theory being fundamental for this article. This unification should overcome the traditional static description of language and integrate the idea of communicative interaction into linguistics. This approach seems to be the most effective for studying ethnocultural characteristics of communication and forming the model of a linguistic identity that dynamically combines linguistic and communicative parameters. While combining achievements of linguistic and communication theories, we can comprehensively solve the problem of personality in the language environment and benefit both sciences.

This study is rather theoretical but it can also be of practical use for the person's linguistic identification and linguistic aesthetic training during classes for the study of some native or foreign language. We should emphasize that an adequate description of a communication system and linguistic identity as its part is achievable only at the level of linguocultural complexes containing psychological, social, ethical and other components reflected in the national language.

\section{CONCLUSION}

Therefore, an ethnocultural trace in the logical-semantic and syntactic structure of utterances can be revealed through the analysis of specific relations of proposition, modus and dictum in national languages. To determine the ethnostratum of utterances, we should consider the following phenomena:

1. The structure of proposition (perceptual and functional characteristics of objects, conceptual preferences).

2. The nature of modus (preferred modality).

3. Specific nomination (characteristics of dictum).

Each stage is considered in relation to communication goals of speech acts, which are universal and nation-related in methods of their achievement.

Thus, proposition, modus and dictum are the main components of the semantic structure of utterances and can act as factors for detecting ethnocultural strata in linguistic signs. Features of national communication are manifested in the preferred format of these structures in utterances and are often associated with the implementation of secondary nomination. Secondary nomination (metaphorical or metonymic) has an ethnocultural character. The choice of secondary motivating features is not accidental and is explained by a peculiar national worldview. Ethnocultural traces in linguistic signs can be determined through the analysis of relationships between proposition, modus and dictum in compositional speech structures.

While considering these phenomena from the ethnocultural viewpoint, we ultimately focus on forming the model of national linguistic identity. National linguistic identity is a relatively rigid system with invariant and variable elements, which reflect patterns of the communication process implemented by a person and the modelability of this phenomenon with the scheme of language ethnotypes.

The model of a language ethnotype is not a language model or a model of its individual subsystems, but rather a model of the communicator's behavior revealed through their relation to natural language, interlocutors and communication information. In fact, this model is nothing else but a metamodel that reflects the individual's ethnocultural communication priorities. Communication behavior is explained by the fact that a person is immersed in the world of meanings, problems and relationships shared by most of their linguocultural community. Thus, an adequate description of a communication system and linguistic identity is achievable only at the level of linguocultural complexes containing, in particular, cognitive, semantic and pragmatic components that can be found in the semantic structure of linguistic signs.

\section{REFERENCES}

1. S.G. Vorkachev, "Lingvokulturologiya, yazykovaya lichnost, kontsept: stanovlenie antropotsentricheskoi paradigmy v yazykoznanii” [Cultural linguistics, linguistic identity, concept: the development of an anthropocentric paradigm in linguistics]. Filol. nauki, 1, 2001, pp. 64-72.

2. E.A. Ogneva, A.A. Kutsenko, Y.I. Kireeva, I.G. Besedina, I.A. Danilenko, "Fiction cognitive coordinates", Journal of Language and Literature, 5(4), 2014, pp. 51-54.

3. G. Gleeson, "Vvedenie v deskriptivnuyu lingvistiku" [Introduction to descriptive linguistics]. Moscow: Editorial URSS, 2008, p. 494.

4. V.I. Karasik, "Yazykovoe proyavlenie lichnosti": monograph; Nauchno-issledovatelskaya laboratoriya "Aksiologicheskaya lingvistika" [the 2nd stereotyped edition]. Moscow: Gnozis, 2015, p. 383.

5. V.G. Gak, "Teoreticheskaya grammatika frantsuzskogo yazyka" [The theoretical grammar of the French language]. Moscow: Dobrosvet, 2000, p. 832.

6. Z.I. Komarova, "Metodologiya, metod, metodika i tekhnologiya nauchnykh issledovanii v lingvistike": uchebnoe posobie [Methodology, methods, principles and technologies of scientific research in the sphere of linguistics: student's textbook]. Yekaterinburg: Izd-vo UrFU, 2012, p 818.

7. E.A. Ogneva, "Spetsifika markerov neverbalnogo koda v arkhitektonike tekstovoi kognitivnoi stseny (na materiale proizvedeniya D. Dyu More "Rebekka")" [Specific markers of a non-verbal code in the architectonics of a text cognitive scene (as exemplified by the novel "Rebecca" by D.D. du Maurier)]. Nizhny Novgorod, Filologicheskii aspect, 6(26), 2017, 132-140.

8. W.O. Quine, "Word and object". N.Y., 1960, pp. 197-250.

9. L. Wittgenstein, "Selected works: Logical and philosophical treatise". Moscow: Izdatelskii dom "Territoriya budushchego", 2005. 440 pp.

10. S.D. Katsnelson, "Soderzhanie slova, znachenie i oboznachenie" [The content, meaning and denotation of a word]. Moscow: Editorial URSS, 2004, p. 112.

11. S.D. Katsnelson, "Tipologiya yazyka i rechevoe myshlenie" [Language typology and verbal thinking]. Moscow: Editorial URSS, 2002, p. 220. 
12. N.D. Arutyunova, "Predlozhenie i ego smysl: Logiko-semanticheskie problem" [Sentence and its meaning: Logical and semantic problems]. Moscow: LKI, seriya: Lingvisticheskoe nasledie XX veka, 2007, p. 382.

13. V.G. Gak, "K probleme semanticheskoi sintagmatiki" [The problem of semantic syntagmatics]. Problemy strukturnoi lingvistiki. Moscow: Nauka, 1972, pp. 367-395.

14. A.P. Sedykh, "Natsionalnaya literatura i kommunikativnaya kultura natsii" [National literature and communicative culture], Vestnik Moskovskogo gorodskogo pedagogicheskogo universiteta. Seriya: Filologiya. Teoriya yazyka. Yazykovoe obrazovanie, 2(10), 2012, pp. 16-20.

15. N.D. Arutyunova, "Tipy yazykovykh znachenii. Otsenka. Sobytie. Fakt" [Types of linguistic meanings. Evaluation. Event. Fact]. Moscow: Nauka, 1988, p. 338

16. A.P. Sedykh, L.M. Buzinova, N.V. Bakirova, N.S. Tsvetova, B.N. Kovalenko, "The Sign, Linguistic Analysis, Idioethnic Interpretation of Communication and Linguistic Persona", International Journal of Engineering and Technology (UAE), 7(4(38)), 2018, pp. 100-104.

17. V.V. Vinogradov, "Osnovnye tipy leksicheskikh znachenii slova" [Basic types of linguistic meanings]. Voprosy yazykoznaniya, 5, 1977, pp. 7-18.

18. Pruvost, J., "Le Dico des Dictionnaires". Paris: JCLattès, 2014, p. 538. 